\title{
valiação do Nível de Maturidade da Indústria 4.0: 0 Caso de uma
Empresa Estratégica de Defesa
}

Recebido: 02/07/2019

Aprovado: 07/11/2019

\author{
Marcus Vinicius Gonçalves da Silva ${ }^{1}$ \\ Clarissa Figueredo Rocha²
}

Objetivo: Avaliar o nível de maturidade de uma Empresa Estratégica de Defesa (EED) sob a ótica dos conceitos da Indústria 4.0.

Método: A pesquisa classifica-se em bibliográfica, qualitativa e descritiva, e utiliza-se do questionário desenvolvido pela Fundação IMPULS, empresa de consultoria alemã, traduzido e adaptado para este estudo, no caso da Indústria de Material Bélico do Brasil (IMBEL).

Originalidade/Relevância: Um dos gaps no estudo da Indústria 4.0 no Brasil é a ausência de evidências empíricas sobre os impactos que as tecnologias decorrentes desse novo paradigma podem contribuir para o desempenho operacional das empresas. Diante dessa nova tendência, faz-se necessário analisar seus impactos nas empresas, de forma empírica, ao relacionar os construtos teóricos desenvolvidos e a realidade das empresas.

Resultados: Os resultados revelam que a empresa analisada apresenta um nível de maturidade intermediário, categorizada como aprendiz em um modelo de maturidade da Indústria 4.0 .

Contribuições metodológicas: A pesquisa contribui com o desenvolvimento empírico de um modelo e fornece um instrumento de análise da maturidade da Indústria 4.0 que poderá ser utilizado em empresas de diferentes setores.

Contribuições para a gestão: O questionário elaborado neste estudo (Apêndice), pode ser utilizado por outras Empresas Estratégicas de Defesa, além de outras empresas de manufatura de diferentes setores, para que possam avaliar o nível de maturidade da Indústria 4.0, com a finalidade de identificar as estratégias e o status de implementação desse novo modelo.

Palavras-chave: Indústria 4.0. Avaliação. Defesa. Empresas Estratégicas de Defesa. IMBEL.

\section{Como citar:}

Silva, M., \& Rocha, C. (2020). Avaliação do Nível de Maturidade da Indústria 4.0: O Caso de uma Empresa Estratégica de Defesa. Future Studies Research Journal: Trends and Strategies [FSRJ], 12(1), 31-59. doi:https://doi.org/10.24023/FutureJournal/2175-5825/2020.v12i1.455

\footnotetext{
${ }^{1}$ PUCPR - Pontifícia Universidade Católica do Paraná, Curitiba (Brasil). E-mail: marvin.gsilva@gmail.com Orcid id: https://orcid.org/0000-0003-2145-0871

2 PUCPR - Pontifícia Universidade Católica do Paraná, Curitiba (Brasil). E-mail: kaclaia@gmail.com Orcid id: http://orcid.org/0000-0002-7831-9412
} 


\begin{abstract}
Purpose - This article aims to evaluate the maturity level of a Strategic Defense Company (EED), from the perspective of Industry 4.0 concepts. The EED are characterized by high technological training and the ability to supply Strategic Defense Products (PED) to the Brazilian Armed Forces.

Theoretical framework - The term Industry 4.0 has become one of the most recurring topics for the global manufacturing sector and in the academic world (Kagermann et al., 2013), however, academic literature on this topic is still scarce (Qin, Liu \& Grosvenor, 2016). One of the problems that stands out is the lack of empirical evidence on the impacts that technologies of Industry 4.0 can have on the operational performance of companies. Instead of this new trend being accepted as dogma, it is necessary to prove its effects on companies, empirically. In this context, this study seeks answers to the following research question: What is the maturity level of Industry 4.0 in Strategic Defense Companies?
\end{abstract}

Methodology - The research is classified in bibliographic, qualitative and descriptive, and uses the survey developed by the IMPULS Foundation, german consulting company, translated and adapted for this study, in the case of the Brazilian Military Material Industry (IMBEL).

Findings - The results reveal that the analyzed company has an intermediate maturity level, categorized as learner in an Industry 4.0 maturity model.

Research, Practical \& Social implications - The research contributes to the empirical development of a model and provides an instrument for analyzing the maturity of Industry 4.0 that can be used in companies from different sectors. Regarding research limitations, it is pointed out that the empirically evaluated data could be validated through descriptive statistics, which would certainly generate greater confidence in the results, however, the study should have a larger sample of participating companies, not being the subject of this study.

Originality - One of the gaps in the study of Industry 4.0, in Brazil, is the absence of empirical evidence on the impacts of enabling technologies of this new paradigma, and how they can contribute to the performance of companies. In view of this new tendency, it is necessary to analyze its impacts on companies, seeking to relate the theoretical constructs developed and the reality observed in companies.

Keywords - Industry 4.0. Assessment. Defense. Strategic Defense Companies. IMBEL.

\title{
How to cite the article:
}

Silva, M., \& Rocha, C. (2020). Assessment of Industry Maturity Level 4.0: The Case of a Strategic Defense Company. Future Studies Research Journal: Trends and Strategies, 12(1), 31-59. doi:https://doi.org/10.24023/FutureJournal/2175-5825/2020.v12i1.455 


\section{valuación del Nivel de Madurez de la Industria 4.0: El Caso de Uma Empresa de Defensa Estratégica}

\section{Resumen}

Objetivo: evaluar el nivel de madurez de una empresa de defensa estratégica (DSE) desde la perspectiva de los conceptos de la Industria 4.0.

Método: La investigación se clasifica en bibliográfica, cualitativa y descriptiva, y utiliza el cuestionario desarrollado por la Fundación IMPULS, una empresa consultora alemana, traducida y adaptada para este estudio, en el caso de la Industria de Materiales Militares de Brasil (IMBEL).

Originalidad/Relevancia: Una de las lagunas en el estudio de la Industria 4.0 en Brasil es la ausencia de evidencia empírica sobre los impactos que las tecnologías resultantes de este nuevo paradigma pueden contribuir al desempeño operativo de las empresas. Ante esta nueva tendencia, es necesario analizar sus impactos en las empresas, de forma empírica, relacionando los constructos teóricos desarrollados y la realidad de las empresas.

Resultados: Los resultados revelan que la empresa analizada tiene un nivel de madurez intermedio, categorizado como aprendiz en un modelo de madurez de la Industria 4.0.

Contribuciones metodológicas: la investigación contribuye al desarrollo empírico de un modelo y proporciona un instrumento para analizar la madurez de la Industria 4.0 que se puede utilizar en empresas de diferentes sectores.

Contribuciones a la gestión: el cuestionario preparado en este estudio (Apéndice), puede ser utilizado por otras Empresas de Defensa Estratégica, además de otras empresas manufactureras de diferentes sectores, para que puedan evaluar el nivel de madurez de la Industria 4.0, con el fin de Identificar las estrategias y el estado de implementación de este nuevo modelo.

Palabras clave: Industria 4.0. Evaluación. Defensa. Empresas de Defensa Estrategica. IMBEL. 


\section{INTRODUÇÃO}

A Indústria 4.0 começou com uma iniciativa do governo alemão para desenvolver o conceito de fábricas inteligentes - fábricas com alto grau de autonomia e flexibilidade, integradas em toda a cadeia de valor e no ciclo de vida do produto (Wang, Wan, Zhang, Li \& Zhang, 2016; Tao et al., 2018) -, visando maior produtividade e eficiência do setor industrial daquele país e novas oportunidades de mercados. A iniciativa contou com parcerias entre universidades e empresas, com o objetivo de desenvolver competências e tecnologias necessárias para integrar as fábricas inteligentes (Kagermann, Wahlster \& Helbig, 2013).

Por se tratar de um conceito recente, os primeiros estudos provêm das áreas de consultoria ou pesquisas industriais (Berger, 2014; Wee, Kelly, Cattell \& Breunig, 2015). Contudo, a maior parte desses estudos tratam de aspectos específicos da implementação de algumas tecnologias para a Indústria 4.0, sem avaliá-la como um conceito abrangente com implicações para a gestão de operações.

Um dos problemas que se destaca é a ausência de evidências empíricas sobre os impactos que as tecnologias da Indústria 4.0 podem acarretar no desempenho operacional das empresas. Ao invés desta nova tendência ser aceita como um dogma, se faz necessário comprovar seus efeitos nas empresas, de forma empírica. Nesse contexto, neste estudo busca-se responder a seguinte questão de pesquisa: Qual o nível de maturidade da Indústria 4.0 nas Empresas Estratégicas de Defesa?

Para tanto, este artigo se encontra dividido em seis partes, incluindo esta breve introdução. A segunda parte é composta de uma fundamentação teórica, abarcando os conceitos da Indústria 4.0; o panorama das empresas estratégicas de defesa no país; e, descreve alguns modelos de avaliação da Indústria 4.0. Na terceira parte apresenta-se o percurso metodológico da pesquisa para explorar o tema, coletar e analisar os dados. A quarta parte apresenta e caracteriza o caso em estudo, a IMBEL. $\mathrm{Na}$ quinta parte é feita a análise das respostas coletadas e apresentado os resultados da avaliação da maturidade da IMBEL, conforme as seis dimensões de análise e a categorização. Por último, na sexta parte, são feitas as considerações finais.

\section{REVISÃO BIBLIOGRÁFICA}

\subsection{INDÚSTRIA 4.0}

A terminologia Indústria 4.0 teve origem na Alemanha, em um evento realizado na Feira de Hannover, no ano de 2011, o que representou o início da $4^{a}$ Revolução Industrial (Lee, 2013). No entanto, outros países adotaram terminologias similares, como os EUA, "Internet Industrial" e China com "Internet+" (Wang et al., 2016).

O termo Indústria 4.0 tem se tornado um dos tópicos mais recorrentes para o setor manufatureiro global e no mundo acadêmico (Kagermann et al., 2013), no entanto, a literatura acadêmica sobre esse tema ainda é escassa (Qin, Liu \& Grosvenor, 2016; Gontijo \& Motta Alves, 2019).

Para Dombrowski e Wagner (2014), a categorização de uma nova Revolução Industrial constitui uma mudança significativa nos sistemas técnicos, econômicos ou sociais dentro da indústria, isto é, uma mudança de paradigma no modelo de produção 
(Moraes \& Monteiro, 2019). Depreende-se que a $4^{a}$ revolução industrial demandará novos processos e produtos com alto conteúdo tecnológico.

Schumacher, Erol e Sihn (2016) revelam que as organizações estão encontrando dificuldades para relacionar a visão futura da Indústria 4.0 aos negócios, a fim de fornecer benefícios significativos para justificar o grande investimento financeiro. Nessa mesma perspectiva, Qin et al. (2016) observam que, de modo geral, as empresas de manufatura ainda se encontram em estágio desordenado e desorganizado sobre a percepção das possibilidades e limitações da Indústria 4.0.

\subsection{EMPRESAS ESTRATÉGICAS DE DEFESA (EED)}

A política industrial denominada Plano Brasil Maior (PBM) contempla o incentivo para "as atividades de empresas com potencial de desenvolvimento tecnológico de interesse da Defesa Nacional, assim como o uso do poder de compra do Estado para sustentar o desenvolvimento e crescimento dos negócios" (Correa Filho, Barros, Castro, Fonseca \& Gornsztejn, 2013, p. 403).

Sucintamente, as EED caracterizam-se pela alta capacitação tecnológica; pela capacidade de fornecer Produtos Estratégicos de Defesa às Forças Armadas brasileiras; e, o controle de capital majoritariamente nacional.

O credenciamento das EED compete à Comissão Mista da Indústria de Defesa (CMID), criada por meio do Decreto no 7.970/2013 (Brasil, 2013), a qual tem a competência para assessorar o ministro da Defesa em processos decisórios e em proposições de atos relacionados à indústria nacional de defesa (Ministério da Defesa [MD], 2019). Conforme dados de 2019, publicado no site da Secretaria da Produtos de Defesa (SEPROD) do Ministério da Defesa, há 93 (noventa e três) EED cadastradas, sendo que $78,49 \%(n=73)$ estão localizadas na região sudeste (46 no estado de São Paulo, 21 no estado do Rio de Janeiro e seis no estado de Minas Gerais), 8,6\% ( $n=8)$ no Rio Grande do Sul, 7,53\% ( $n=7)$ em Santa Catarina, $2,15 \%(n=2)$ no Paraná, e os $3,23 \%$ restantes, correspondem a uma EED localizada em cada um dos estados de Pernambuco, Ceará e Distrito Federal, respectivamente, conforme Figura 1.

Figura 1. Distribuição das Empresas Estratégica de Defesa, por estados

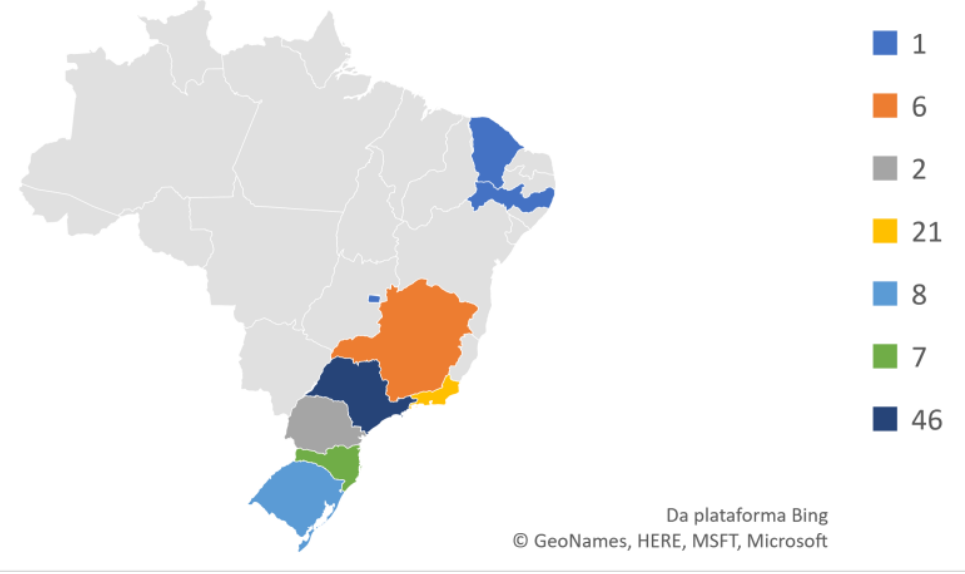

Fonte: Elaboração própria a partir de Centro de Apoio a Sistemas Logísticos de Defesa [Caslode] (2019). 


\subsection{MODELOS DE AVALIAÇÃO DE MATURIDADE DA INDÚSTRIA 4.0}

Os modelos de avaliação de maturidade são descritos como instrumentos de análise de melhoria de desempenho sistemático e contínuo (Langston \& Ghanbaripour, 2016). Backlund, Chroneer e Sundqvist (2014) sugerem que as capacidades de uma organização podem ser gerenciadas como uma estrutura e, assim, serem medidas para a maturidade.

Alguns modelos de avaliação da Indústria 4.0 foram desenvolvidos por empresas de consultoria, como o IMPULS - Industrie 4.0 Readiness, de Lichtblau et al. (2015), o Industry 4.0 Self Assessment, de PricewaterhouseCoopers (PWC, 2016) e o Industrie 4.0 Maturity Index, de Schuh, Anderl, Gausemeier, ten Hompel \& Wahlster (2017). Nota-se que há poucos modelos de avaliação para a Indústria 4.0, existindo uma lacuna no meio acadêmico, na construção de novos modelos que permitam avaliar o nível de maturidade das empresas de defesa no Brasil. Quanto às contribuições para a prática organizacional, Rocha et al. (2018) observam que as tecnologias habilitadoras da Indústria 4.0 podem contribuir para alavancar a competitividade das empresas e gerar valor agregado.

O modelo IMPULS - Industrie 4.0 Readiness, desenvolvido por Lichtblau et al. (2015), contém um conjunto de dados e dimensões abrangentes. Schumacher et al. (2016) apontam que o modelo é cientificamente bem fundamentado e sua estrutura e resultados são explicados de modos transparentes.

O modelo de Lichtblau et al. (2015) relaciona-se com áreas potenciais para a transformação digital, e engloba seis dimensões: i) estratégia e organização, ii) fábrica inteligente, iii) operações inteligentes, iv) produtos inteligentes, v) serviços orientados por dados e vi) funcionários. Para esses autores, a transformação digital proporcionará vantagem competitiva para a indústria, seja por meio de maior automação e produtos personalizados ao custo de um produto produzido em massa; expansão dos portfólio de serviços, visando maior receita de produtos digitalmente refinados; e, o acesso a novos mercados.

A dimensão Estratégia e Organização (EO) refere-se à oportunidade de desenvolver modelos de negócios totalmente novos. Por esse motivo, a implementação do uso de tecnologias digitais é de grande importância estratégica. A dimensão Fábrica Inteligente (FI) caracteriza-se pela interconectividade com toda a cadeia de valor e o ciclo de vida do produto. A dimensão Operações Inteligentes (OI) refere-se à integração horizontal e vertical da empresa, o que permite um planejamento e controle flexível da produção. A dimensão Produtos Inteligentes (PI) são objetos físicos equipados com TICs que podem interagir com o ambiente, por 
meio da utilização de tecnologia de sensores para registrar o status em tempo real e oferecer várias funcionalidades adicionais na operação. Serviços orientados por dados (SOD) incluem o consumo otimizado de recursos de máquinas, disponibilidade, desempenho e qualidade através de configurações de parâmetros otimizadas etc. Os Funcionários (F) colaboram com as empresas para a implementação da Indústria 4.0, ao mesmo tempo que são os mais afetados pelas mudanças promovidas pela transformação digital, pela exigência de novas habilidades e qualificações. Isso aponta para a necessidade das empresas preparem seus funcionários para essas mudanças por meio de treinamento apropriado e educação continuada (Lichtblau et al., 2015).

\section{METODOLOGIA}

Por meio de uma análise bibliográfica, os artigos científicos utilizados na fundamentação teórica foram localizados na base de dados Scopus, em razão de sua relevância internacional.

Na primeira etapa, por meio de uma busca realizada no dia 02 de maio de 2019, foram utilizadas as Keywords: "Industry 4.0", "defence" e "assessment", e o operador booleano "and", sendo que o artigo de Bibby e Dehe (2018), Defining and assessing industry 4.0 maturity levels-case of the defence sector, foi o único que teve aproximação com o tema em estudo, ou seja, a avaliação da maturidade da Indústria 4.0 no setor de defesa.

Numa segunda etapa de pesquisa, foi utilizado o termo "Industry 4.0" no campo "title-abs-key", documentos tipo "article" e, selecionado o ano de publicação dos artigos, acima de 2010, e limitado no país "Brazil".

Foram localizados 21 artigos, sendo que após uma filtragem, foram excluídos aqueles que não eram "Open Access", restando apenas três artigos de autores brasileiros: The Role of Interoperability in The Fourth Industrial Revolution Era (Liao et al., 2017), Opportunities Assessment of Product Development Process in Industry 4.0 (Santos et al., 2017) e, Mapping the Conceptual Relationship among Data Analysis, Knowledge Generation and Decision-making in Industrial Processes (Dos Santos et al. ,2017). A leitura desses artigos, colaborou para a fundamentação teórica do estudo.

A pesquisa utiliza uma combinação de coleta de dados, tendo como instrumento de pesquisa o questionário formulado pela Fundação Alemã IMPULS, traduzido e adaptado (Apêndice), a fim de se testar e validar o modelo de forma empírica.

Borsa, Damásio e Bandeira (2012) e Silva et al. (2018) apontam que ao adaptar um instrumento de pesquisa, deve-se considerar a conveniência dos conceitos e domínios tomados pelo instrumento original, bem como considerar a adequação de 
cada item em termos da possibilidade de representar tais conceitos e domínios na nova população-alvo.

A estratégia adotada foi o estudo de um caso único, a Indústria de Material Bélico do Brasil - $\operatorname{IMBEL}^{\circledR}$. No que se refere à abordagem, consiste em uma pesquisa qualitativa, pois se pretende visualizar o fenômeno (maturidade da Indústria 4.0 em uma Empresa Estratégica de Defesa) a fim de agregar o conhecimento necessário, pois a intenção é fomentar a proposição de estudos futuros e a exploração sob novos enfoques (Godoy, 1995).

\subsection{ANÁLISE DOS DADOS}

A análise dos dados consistiu em definir um dos seis perfis da Maturidade da Indústria 4.0, conforme os respectivos níveis - 5: Alto desempenho, 4: Especialista, 3: Experiente, 2: Intermediário, 1: Iniciante, e 0: Outsider, e as respectivas características, de forma qualitativa (Quadros 1 a 6 ).

Quadro 1. Estratégia e Organização - Níveis, perfis e características

\begin{tabular}{|c|c|c|c|}
\hline \multirow{7}{*}{ 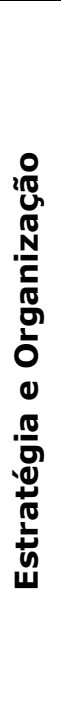 } & NÍVEL & PERFIL & CARACTERÍSTICAS \\
\hline & 5 & Alto desempenho & $\begin{array}{l}\text { - Estratégia implementada e regularmente revisada } \\
\text { - Investimentos na Indústria } 4.0 \text { em toda a empresa } \\
\text { - Gestão de inovação uniforme e estabelecida em toda a } \\
\text { empresa }\end{array}$ \\
\hline & 4 & Especialista & $\begin{array}{l}\text { - Estratégia em implementação e revista esporadicamente } \\
\text { - Investimentos na Indústria } 4.0 \text { em múltiplas áreas } \\
\text { - Gestão da inovação estabelecida em múltiplos } \\
\text { departamentos }\end{array}$ \\
\hline & 3 & Experiente & $\begin{array}{l}\text { - Estratégia para a Indústria } 4.0 \text { formulada } \\
\text { - Investimentos para a Indústria } 4.0 \text { em algumas áreas } \\
\text { - Gestão da inovação em áreas isoladas }\end{array}$ \\
\hline & 2 & Intermediário & $\begin{array}{l}\text { - Estratégia para a Indústria } 4.0 \text { desenvolvida e sistema de } \\
\text { indicadores definidos } \\
\text { - Investimentos na Indústria } 4.0 \text { a um nível baixo }\end{array}$ \\
\hline & 1 & Iniciante & $\begin{array}{l}\text { - Iniciativas piloto nos departamentos } \\
\text { - Investimentos iniciais na Indústria } 4.0\end{array}$ \\
\hline & $\mathbf{0}$ & Outsider & - Nenhum requisito foi cumprido \\
\hline
\end{tabular}

Fonte: Adaptado de Lichtblau et al. (2015). 
Quadro 2. Fábrica Inteligente - Níveis, perfis e características

\begin{tabular}{|c|c|c|c|}
\hline \multirow{7}{*}{ 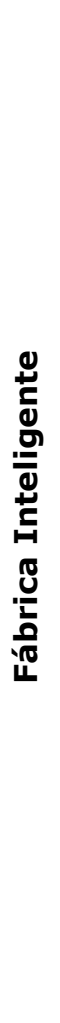 } & NÍVEL & PERFIL & CARACTERÍSTICAS \\
\hline & 5 & $\begin{array}{c}\text { Alto } \\
\text { desempenho }\end{array}$ & $\begin{array}{l}\text { - A infraestrutura de equipamentos satisfaz as funcionalidades } \\
\text { futuras } \\
\text { - Todos os dados são coletados e utilizados } \\
\text { - Suporte abrangente ao sistema de TI dos processos }\end{array}$ \\
\hline & 4 & Especialista & $\begin{array}{l}\text { - A infraestrutura atual dos equipamentos atende aos } \\
\text { requisitos ou é atualizável } \\
\text { - A maioria dos dados são coletados e alguns são utilizados } \\
\text { - Suporte abrangente de TI de processos (integrados ao } \\
\text { sistema) }\end{array}$ \\
\hline & 3 & Experiente & $\begin{array}{l}\text { - Funcionalidades futuras (parcialmente) satisfeitas ou } \\
\text { totalmente atualizáveis } \\
\text { - Dados relevantes são coletados digitalmente e utilizados em } \\
\text { algumas áreas } \\
\text { - Sistemas de TI suportam processos e são ligados através de } \\
\text { interfaces }\end{array}$ \\
\hline & 2 & Intermediário & $\begin{array}{l}\text { - Funcionalidades futuras (parcialmente) satisfeitas ou } \\
\text { atualizáveis até certo ponto } \\
\text { - Os dados são coletados (mas em grande parte } \\
\text { manualmente) e utilizados para algumas atividades } \\
\text { - Algumas áreas da empresa são apoiadas por sistemas de TI } \\
\text { e sistemas integrados }\end{array}$ \\
\hline & 1 & Iniciante & $\begin{array}{l}\text { - A infraestrutura atual do equipamento satisfaz alguns dos } \\
\text { requisitos futuros } \\
\text { - Processo empresarial principal suportado pelo sistema de TI }\end{array}$ \\
\hline & $\mathbf{0}$ & Outsider & requisitos atendidos \\
\hline
\end{tabular}

Fonte: Adaptado de Lichtblau et al. (2015).

Quadro 3. Operações Inteligentes - Níveis, perfis e características

\begin{tabular}{|c|c|c|c|}
\hline \multirow{7}{*}{ 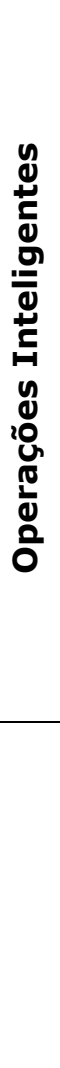 } & NIVEL & PERFIL & CARACTERÍSTICAS \\
\hline & 5 & $\begin{array}{c}\text { Alto } \\
\text { desempenho }\end{array}$ & $\begin{array}{l}\text { - Compartilhamento completo de informações integradas } \\
\text { ao sistema } \\
\text { - Processos autônomos de controle e autoreação } \\
\text { implementados } \\
\text { - Segurança abrangente de TI e soluções em nuvem } \\
\text { implementadas }\end{array}$ \\
\hline & 4 & Especialista & $\begin{array}{l}\text { - Compartilhamento de informações de longo alcance } \\
\text { integrado ao sistema } \\
\text { - Teste de controle autônomo e processos de autoreação } \\
\text { - Segurança de TI de longo alcance e soluções em nuvem } \\
\text { em uso }\end{array}$ \\
\hline & 3 & Experiente & $\begin{array}{l}\text { - Algum compartilhamento de informações integrado ao } \\
\text { sistema } \\
\text { - Soluções de segurança de TI parcialmente } \\
\text { implementadas } \\
\text { - Soluções iniciais para software baseado em nuvem, } \\
\text { armazenamento e análise de dados }\end{array}$ \\
\hline & 2 & Intermediário & $\begin{array}{l}\text { - Compartilhamento interno de informações parcialmente } \\
\text { implementadas } \\
\text { - Múltiplas soluções de segurança de TI planejadas ou } \\
\text { soluções iniciais em desenvolvimento }\end{array}$ \\
\hline & 1 & Iniciante & $\begin{array}{l}\text { - Primeiros passos para o compartilhamento } \\
\text { informações internas e integradas ao sistema } \\
\text { - Soluções iniciais de segurança de TI planejadas } \\
\end{array}$ \\
\hline & $\mathbf{0}$ & Outsider & - Não há requisitos atendidos \\
\hline
\end{tabular}

Fonte: Adaptado de Lichtblau et al. (2015). 
Quadro 4. Produtos Inteligentes - Níveis, perfis e características

\begin{tabular}{|c|c|c|c|}
\hline \multirow{7}{*}{ 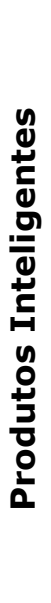 } & NÍVEL & PERFIL & CARACTERÍSTICAS \\
\hline & 5 & $\begin{array}{c}\text { Alto } \\
\text { desempenho }\end{array}$ & $\begin{array}{l}\text { - Os produtos apresentam funcionalidades adicionais } \\
\text { abrangentes } \\
\text { - Uso abrangente de dados coletados para várias funções }\end{array}$ \\
\hline & 4 & Especialista & $\begin{array}{l}\text { - Os produtos apresentam funcionalidades adicionais em } \\
\text { diferentes áreas } \\
\text { - Uso direcionado de dados coletados para determinadas } \\
\text { funções }\end{array}$ \\
\hline & 3 & Experiente & $\begin{array}{l}\text { - Os produtos têm várias funcionalidades adicionais } \\
\text { interconectadas } \\
\text { - Apenas alguns dados coletados são utilizados para análise }\end{array}$ \\
\hline & 2 & Intermediário & $\begin{array}{l}\text { - Produtos têm primeiros sinais de funcionalidades adicionais } \\
\text { - Os dados são coletados, mas não analisados e utilizados }\end{array}$ \\
\hline & 1 & Iniciante & - Produtos têm primeiros sinais de funcionalidades adicionais \\
\hline & $\mathbf{0}$ & Outsider & - Não há requisitos atendidos \\
\hline
\end{tabular}

Fonte: Adaptado de Lichtblau et al. (2015).

Quadro 5. Serviços Orientados por Dados - Níveis, perfis e características

\begin{tabular}{|c|c|c|c|}
\hline \multirow{7}{*}{ 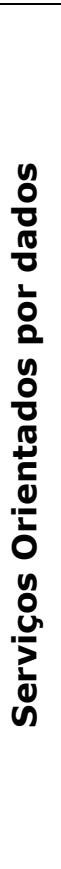 } & NÍVEL & PERFIL & CARACTERÍSTICAS \\
\hline & 5 & $\begin{array}{l}\text { Alto } \\
\text { desempenho }\end{array}$ & $\begin{array}{l}\text { - Serviços acionados por dados por meio da integração com o } \\
\text { cliente } \\
\text { - Receitas geradas por serviços (>10\%) } \\
\text { - Alta taxa de uso de dados (>50\% dos dados coletados) }\end{array}$ \\
\hline & 4 & Especialista & $\begin{array}{l}\text { - Serviços acionados por dados por meio da integração com o } \\
\text { cliente } \\
\text { - Receitas geradas por serviços (<10\%) } \\
\text { - Uso de dados ( } 20 \% \text { a } 50 \% \text { dos dados coletados) }\end{array}$ \\
\hline & 3 & Experiente & $\begin{array}{l}\text { - Serviços baseados em dados, mas sem integração com o } \\
\text { cliente } \\
\text { - Baixa receita gerada por serviços }(<7,5 \%) \\
\text { - Uso de dados ( } 20 \% \text { a } 50 \% \text { dos dados coletados) }\end{array}$ \\
\hline & 2 & Intermediário & $\begin{array}{l}\text { - Serviços baseados em dados, mas sem integração com o } \\
\text { cliente } \\
\text { - Baixa receita gerada por serviços }(<2,5 \%) \\
\text { - Baixo uso de dados da fase de uso ( }<20 \% \text { dos dados } \\
\text { coletados) }\end{array}$ \\
\hline & 1 & Iniciante & $\begin{array}{l}\text { - Serviços baseados em dados, mas sem integração com o } \\
\text { cliente } \\
\text { - Receita inicial gerada por serviços }(<1 \%)\end{array}$ \\
\hline & $\mathbf{0}$ & Outsider & - Não há requisitos atendidos \\
\hline
\end{tabular}

Fonte: Adaptado de Lichtblau et al. (2015).

Quadro 6. Funcionários - Níveis, perfis e características

\begin{tabular}{|l|l|l|l|}
\hline \multirow{2}{*}{} & NÍVEL & PERFIL & CARACTERÍSTICAS \\
\cline { 2 - 4 } & $\mathbf{5}$ & $\begin{array}{l}\text { Alto } \\
\text { desempenho }\end{array}$ & $\begin{array}{l}\text { - Os funcionários possuem habilidades em várias áreas } \\
\text { relevantes }\end{array}$ \\
\cline { 2 - 4 } & $\mathbf{4}$ & Especialista & $\begin{array}{l}\text { - Os funcionários possuem níveis de qualificação adequados } \\
\text { em várias áreas relevantes }\end{array}$ \\
\cline { 2 - 4 } & $\mathbf{3}$ & Experiente & $\begin{array}{l}\text { - Os funcionários possuem níveis de qualificação adequados } \\
\text { em algumas áreas relevantes }\end{array}$ \\
\cline { 2 - 4 } & $\mathbf{2}$ & Intermediário & $\begin{array}{l}\text { - Os funcionários têm baixos níveis de qualificação em poucas } \\
\text { áreas relevantes }\end{array}$ \\
\cline { 2 - 4 } & $\mathbf{1}$ & Iniciante & $\begin{array}{l}\text { - Os funcionários têm baixos níveis de habilidade em uma área } \\
\text { relevante }\end{array}$ \\
\cline { 2 - 4 } & $\mathbf{0}$ & Outsider & - Não há requisitos atendidos \\
\hline
\end{tabular}

Fonte: Adaptado de Lichtblau et al. (2015). 
As seis dimensões acima foram agrupadas a fim de categorizar a Indústria 4.0 com base no nível de implementação, conforme o quadro 7.

Quadro 7. Níveis de categorização de implementação da Indústria 4.0

\begin{tabular}{|l|l|l|}
\hline \multicolumn{1}{|c|}{ CATEGORIZAÇÃO } & NÍVEIS & \multicolumn{1}{c|}{ CARACTERÍSTICAS } \\
\hline Recém-chegados (newcomers) & 0 a 1 & $\begin{array}{l}\text { As empresas que nada fizeram ou fizeram muito } \\
\text { pouco em relação à implementação }\end{array}$ \\
\hline Aprendizes (learners) & 2 & $\begin{array}{l}\text { As empresas já deram seus primeiros passos para } \\
\text { a implementação }\end{array}$ \\
\hline Líderes (leaders) & 3 acima & $\begin{array}{l}\text { As empresas possuem estratégias implementadas } \\
\text { e estão à frente das demais empresas do setor, } \\
\text { sendo referência }\end{array}$ \\
\hline
\end{tabular}

Fonte: Adaptado de Lichtblau et al. (2015).

Neste estudo, o resultado do nível de maturidade foi adaptado de Lichtblau et al. (2015), a fim de simplificar a compreensão do método e sua replicação. Assim, a análise constituiu-se em três fases:

- $\quad 1^{\text {a }}$ fase - pontuar, numa escala de 0 a 5, as dimensões E\&O, FI, OI, PI, SOD e F, relacionando, de forma qualitativa, as respostas recebidas no Google Forms com as características de cada dimensão apresentadas nos Quadros 1 a 6.

- $\quad 2^{\mathbf{a}}$ fase - por meio do cálculo de média simples, calcular o escore geral de cada dimensão.

- $\quad 3^{a}$ fase - com o escore geral, categorizar a empresa conforme a implementação da Indústria 4.0 em recém-chegada (newcoming), aprendiz (learner) ou líder (leader) na Indústria 4.0 (Quadro 7).

\section{O CASO DA IMBEL}

A Indústria de Material Bélico do Brasil ${ }^{\circledR}$ (IMBEL), Empresa Estratégica de Defesa (EED), é uma empresa pública dependente, com personalidade jurídica de direito privado, vinculada ao Ministério da Defesa por intermédio do Comando do Exército, e tem a missão de fabricar e comercializar produtos de defesa e segurança para clientes institucionais, especialmente Forças Armadas, Forças Policiais e clientes privados (Indústria de Material Bélico [IMBEL], 2019).

Os principais produtos fabricados e comercializados pela IMBEL são fuzis, pistolas e carabinas; munições de artilharia, de morteiros e de carros de combate; pólvora, explosivos e acessórios; equipamentos de comunicações e eletrônica; e sistemas de abrigos temporários de campanha, humanitários e de defesa civil (IMBEL, 2019). Atualmente, a Empresa tem sua sede instalada em Brasília/DF e suas unidades de produção localizadas nas cidades de Piquete/SP, Rio de Janeiro/RJ, Magé/RJ, Juiz de Fora/MG e Itajubá/MG (IMBEL, 2019). 
A IMBEL tem como visão institucional "fornecer soluções de defesa e segurança com elevado conteúdo tecnológico, mantendo-se apta a atender à mobilização industrial e a fomentar a indústria nacional de defesa" (IMBEL, 2019).

Com essa visão organizacional de futuro, avaliar a maturidade da IMBEL sob a ótica da Indústria 4.0, torna-se uma oportunidade de pesquisa que visa contribuir com o desenvolvimento empírico de um modelo para as empresas estratégicas brasileiras de defesa.

\section{APRESENTAÇÃO E ANÁLISE DOS RESULTADOS}

O questionário foi encaminhado para a IMBEL no dia 29 de maio de 2019, e respondido na mesma data, por um Assessor da Diretoria Industrial, o qual autorizou que os dados da empresa e as respostas fossem publicadas em congressos e periódicos científicos. As respostas iniciais abarcaram: i) Ramo de atividade: produtos de defesa; ii) Porte da empresa: acima de 500 funcionários (grande porte); Nível de conhecimento, apoio e conhecimento das lideranças da empresa em relação à Indústria 4.0: médio-alto, pois as lideranças reconhecem a importância de a empresa definir estratégias para transformação digital.

Nos tópicos seguintes serão apresentadas as seis dimensões da maturidade da Indústria 4.0, analisados em consonância com as respostas da IMBEL recebidas eletronicamente no Google Forms $®$ e tabuladas no Software Excelß.

\subsection{DIMENSÃO - ESTRATÉGIA E ORGANIZAÇÃO (E\&O)}

A Indústria 4.0, mais do que melhorar produtos ou processos existentes por meio do uso de tecnologias digitais, busca oferecer a oportunidade de desenvolver novos modelos de negócios, com a finalidade de aumentar a produtividade e a competitividade. Por essa razão, sua implementação tem sido de grande importância estratégica para as empresas. Para encontrar tais respostas, foram analisados três critérios: i) status da estratégia de implementação; ii) operacionalização e revisão da estratégia através de um sistema de indicadores; e, iii) investimentos.

Tabela 1: E\&O - IMBEL

\begin{tabular}{l|l|l|l}
\hline \multirow{2}{*}{ E\&O } & $\begin{array}{l}\text { Estratégia em } \\
\text { Desenvolvimento. }\end{array}$ & $\begin{array}{l}\text { Sim, nós temos um } \\
\text { sistema de indicadores } \\
\text { que nos dá alguma } \\
\text { orientação. }\end{array}$ & $\begin{array}{l}\text { Produção e a área de TI receberam } \\
\text { médio investimento. As demais } \\
\text { receberam pouco investimento. }\end{array}$ \\
\hline Nível & $\mathbf{1}$ & $\mathbf{2}$ & $\mathbf{2}$ \\
\hline Média & \multicolumn{2}{|c}{ Intermediário } \\
\hline Perfil & \multicolumn{1}{|c}{} \\
\hline
\end{tabular}




\subsection{DIMENSÃO - FÁBRICA INTELIGENTE (FI)}

Uma FI é um ambiente de produção em que os sistemas de produção e logísticos se organizam amplamente sem intervenção humana. Conta com sistemas ciber-físicos (CPS) que conectam os ambientes físico e virtual através de uma infraestrutura de TI: a Internet das Coisas (IoT). Para tanto, requer a comunicação em tempo real entre empresas, sistemas de produção, de informação e pessoas. Quatro critérios foram analisados para se medir a dimensão da FI: i) modelagem digital; ii) infraestrutura de equipamentos; iii) uso de dados; e, iv) sistemas de TI.

Tabela 2: FI - IMBEL

\begin{tabular}{|c|c|c|c|c|}
\hline $\mathbf{F I}$ & $\begin{array}{lr}\text { Menos de 25\% dos } \\
\text { equipamentos } & \text { da } \\
\text { empresa podem ser } \\
\text { controlados através de TI; } \\
\text { comunicação r entre } \\
\text { máquinas para otimização } \\
\text { do processo; e } \\
\text { interoperabilidade } \\
\text { comunicação } \\
\text { máquinas. }\end{array}$ & $\begin{array}{l}\text { A adaptabilidade da } \\
\text { infraestrutura dos } \\
\text { equipamentos somente } \\
\text { para sistemas M2M e } \\
\text { interoperabilidade são } \\
\text { atualizáveis. }\end{array}$ & $\begin{array}{l}\text { A empresa coleta } \\
\text { apenas alguns } \\
\text { dados durante a } \\
\text { produção, mas de } \\
\text { forma manual. }\end{array}$ & $\begin{array}{l}\text { Apenas o ERP (Gestão } \\
\text { de planejamento de } \\
\text { recursos) é utilizado } \\
\text { com interface com o } \\
\text { sistema central. }\end{array}$ \\
\hline Nível & 2 & 2 & 2 & 2 \\
\hline Média & \multicolumn{4}{|c|}{2} \\
\hline Perfil & \multicolumn{4}{|c|}{ Intermediário } \\
\hline
\end{tabular}

Fonte: elaborado pelos autores.

Fórmula: soma dos níveis / 4 = média

\subsection{DIMENSÃO - OPERAÇÕES INTELIGENTES (OI)}

Com o advento da digitalização tornou-se possível introduzir abordagens inteiramente novas para os sistemas de planejamento de produção e o gerenciamento da cadeia de suprimentos. Os requisitos técnicos necessários para esses sistemas realizarem o autocontrole das peças são conhecidos como Operações Inteligentes (OI). A integração dos sistemas de produção oferece uma gama de potencial para aumentar a produtividade, qualidade e flexibilidade (PWC, 2016). A dimensão OI é determinada por quatro critérios: i) compartilhamento de informações, ii) uso de nuvem (cloud computing), iii) segurança de TI, e, iv) processos autônomos. 
Tabela 3: OI - IMBEL

\begin{tabular}{|c|c|c|c|c|c|}
\hline OI & $\begin{array}{l}\text { Somente nos } \\
\text { setores de } \\
\text { Produção e TI há o } \\
\text { compartilha-mento } \\
\text { de informações } \\
\text { internas do sistema } \\
\text { entre departamen- } \\
\text { tos }\end{array}$ & $\begin{array}{l}\text { Nenhum dos } \\
\text { setores há o } \\
\text { compartilhamento } \\
\text { de informações } \\
\text { internas do } \\
\text { sistema com } \\
\text { consumidores } \\
\text { e/ou fornecedores }\end{array}$ & $\begin{array}{l}\text { A linha de } \\
\text { produção } \\
\text { não é guiada } \\
\text { autonoma- } \\
\text { mente }\end{array}$ & $\begin{array}{l}\text { A empresa não } \\
\text { possui processos } \\
\text { que respondam } \\
\text { de forma } \\
\text { autônoma/auto } \\
\text { mática, em } \\
\text { tempo real, às } \\
\text { mudanças que } \\
\text { ocorram durante } \\
\text { a produção }\end{array}$ & $\begin{array}{l}\text { Há soluções } \\
\text { planejadas para a } \\
\text { segurança de dados } \\
\text { por meio de } \\
\text { serviços em nuvem; } \\
\text { e, segurança de } \\
\text { comunicações para } \\
\text { troca de dados com } \\
\text { parceiros de } \\
\text { negócios }\end{array}$ \\
\hline Nível & 1 & 0 & 0 & $\mathbf{0}$ & 2 \\
\hline Média & \multicolumn{5}{|c|}{1} \\
\hline Perfil & \multicolumn{5}{|c|}{ Iniciante } \\
\hline
\end{tabular}

Fonte: elaborado pelos autores.

Fórmula: soma dos níveis / 5 = média aproximada

\subsection{DIMENSÃO - PRODUTOS INTELIGENTES (PI)}

Os PI são um componente vital de um conceito unificado de FI, facilitando a produção automatizada, flexível e eficiente. Os produtos físicos são equipados com componentes de TIC (sensores, RFID etc.) para coletar dados sobre seu ambiente e seu próprio status (Lichtblau et al., 2015). Também é possível monitorar e otimizar o status dos produtos individuais, com aplicações potenciais além da produção.

A utilização de PI durante a fase de utilização possibilita novos serviços - por meio da comunicação entre clientes e fabricantes, por exemplo. A dimensão PI é determinada observando i) as funcionalidades adicionais dos produtos; e, ii) a porcentagem que os dados da fase de uso são analisados.

Tabela 4: PI - IMBEL

\begin{tabular}{l|c|cc}
\hline \multicolumn{1}{c|}{ PI } & $\begin{array}{l}\text { A empresa não possui as funcionalidades de } \\
\text { diagnóstico, preditiva, descritiva e } \\
\text { preventiva nos seus produtos }\end{array}$ & $\begin{array}{l}\text { De } 1 \text { a 20\% dos dados coletados são } \\
\text { utilizados }\end{array}$ \\
\hline Nível & $\mathbf{0}$ & $\mathbf{3}$ \\
\hline Média & \multicolumn{2}{|c}{$\mathbf{2}$} \\
\hline Perfil & \multicolumn{1}{c}{ Intermediário } \\
\hline
\end{tabular}

Fonte: elaborado pelos autores.

Fórmula: soma dos níveis / 2 = média aproximada

\subsection{DIMENSÃO - SERVIÇOS ORIENTADOS POR DADOS (SOD)}

Os SOD buscam alinhar modelos de negócios futuros e aumentar os benefícios para os clientes. O pós-venda se baseará cada vez mais na avaliação e análise dos dados coletados e dependerá da integração em toda a empresa. Os produtos físicos em si devem ser equipados com TIC para que possam enviar, receber ou processar as informações necessárias para os processos operacionais, que por sua vez são a base para serviços digitalizados na fase de uso dos produtos (Lichtblau et al., 2015). 
Os SOD são determinados em três critérios: i) disponibilidade de serviços orientados por dados; ii) compartilhamento de receitas derivadas de dados; e, iii) serviços e compartilhamento de dados.

Tabela 5: SOD - IMBEL

\begin{tabular}{l|c|l|l|l}
\hline SOD & $\begin{array}{l}\text { De 1 a 20\% dos dados } \\
\text { coletados na fase de uso são } \\
\text { utilizados }\end{array}$ & $\begin{array}{l}\text { A empresa não possui } \\
\text { percentual da receita } \\
\text { provenientes dos serviços } \\
\text { orientados por dados }\end{array}$ & $\begin{array}{l}\text { Os dados reunidos no processo } \\
\text { de produção e na fase de uso } \\
\text { não permitem novos serviços e } \\
\text { não há integração com os } \\
\text { clientes }\end{array}$ \\
\hline Nível & $\mathbf{2}$ & $\mathbf{1}$ & $\mathbf{0}$ \\
\hline Média & \multicolumn{1}{|c}{ Iniciante } \\
\hline Perfil
\end{tabular}

Fonte: elaborado pelos autores.

Fórmula: soma dos níveis / 3 = média aproximada

\subsection{DIMENSÃO - FUNCIONÁRIOS (F)}

Por ocasião da transformação digital os funcionários devem passar a adquirir novas habilidades e qualificações, sendo um fator crítico de sucesso, pois as empresas deverão investir em treinamento e educação continuada (Lichtblau et al., 2015). A dimensão Funcionários (F) é determinada pela análise das habilidades dos funcionários em várias áreas da empresa.

Tabela 6: F - IMBEL

\begin{tabular}{l|c}
\hline F & $\begin{array}{l}\text { Os funcionários possuem níveis de qualificação adequados nas áreas de TI, Análise de dados, } \\
\text { Segurança de dados/segurança de comunicações, Desenvolvimento ou aplicação de sistemas } \\
\text { de assistência e software. }\end{array}$ \\
\hline Nível & $\mathbf{4}$ \\
\hline Média & $\mathbf{4}$ \\
\hline Perfil & Especialista \\
\hline
\end{tabular}

Fonte: elaborado pelos autores.

Fórmula: nível / 1 = média

Ao analisar as seis dimensões de maturidade da IMBEL, verifica-se que numa escala de 1 a 5, a empresa obteve as seguintes médias: $\mathrm{E} \& 0=2, \mathrm{FI}=2, \mathrm{OI}=1, \mathrm{PI}=2, \mathrm{SOD}=1, \mathrm{~F}=4$, ilustradas no gráfico 1, elaborado no Software Excelß.

Gráfico 1. Nível de Maturidade da Indústria 4.0 da IMBEL por dimensões.

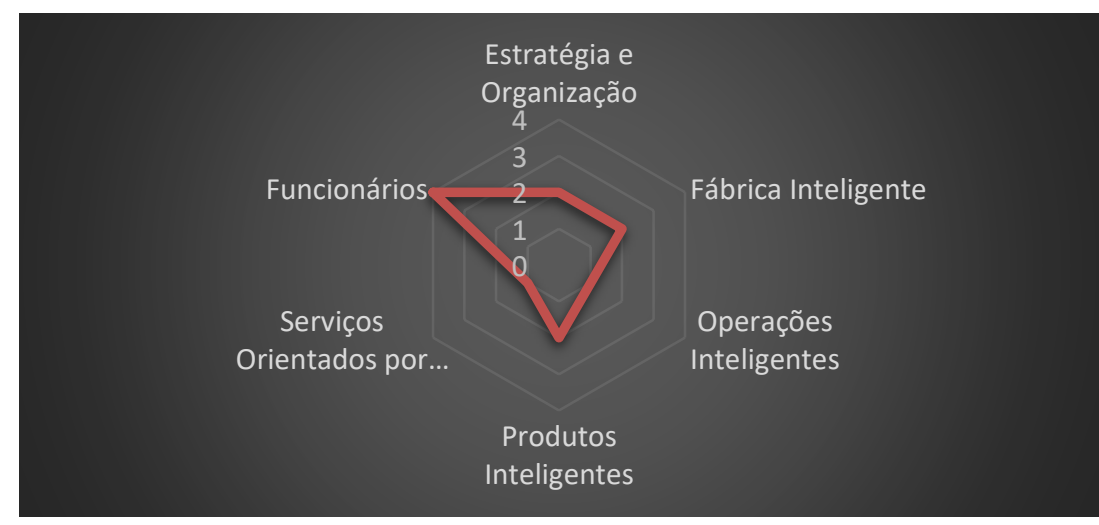

Fonte: elaborado pelos autores. 
Os escores médios de cada dimensão compuseram o cálculo para a obtenção do resultado da avaliação do nível de maturidade da Indústria 4.0 da IMBEL, classificado com o nível intermediário, conforme Tabela 7.

Tabela 7. Nível de Maturidade da Indústria 4.0 da IMBEL

\begin{tabular}{l|c|c|c|c|c|c}
\hline \multicolumn{1}{c|}{ DIMENSÕES } & E\&O & FI & OI & PI & SOD & F \\
\hline Nível & 2 & 2 & 1 & 2 & 1 & 4 \\
\hline Média & \multicolumn{7}{|c}{ Intermediário } \\
\hline Nível de maturidade & \multicolumn{7}{c}{ Inter }
\end{tabular}

Fonte: elaborado pelos autores.

Fórmula: nível $\mathrm{E} \& O$ + nível FI + nível OI + nível PI + nível SOD + nível F / 6 = média

Uma empresa com o nível de maturidade - intermediário - caracteriza-se por estar desenvolvendo uma estratégia para implementar a Indústria 4.0, possui indicadores apropriados para medir o status da implementação e investimentos financeiros estão sendo feitos em algumas áreas da empresa.

Alguns dados de produção são coletados automaticamente e usados de forma limitada, e a infraestrutura dos equipamentos não satisfaz todos os requisitos para expansão futura. O compartilhamento das informações na empresa está integrado aos sistemas até certo ponto, e passos iniciais estão sendo dados para compartilhar as informações com os parceiros de negócios. Existem soluções adequadas de segurança de TI em vigor e se encontram em expansão. No ambiente de produção, a empresa está fabricando produtos com as primeiras funcionalidades adicionais baseadas em TI. $\mathrm{E}$, os funcionários possuem as habilidades necessárias para expansão da Indústria 4.0.

Por último, a Fundação IMPULS caracteriza as empresas com nível de maturidade intermediário em learners (Quadro 7), ou aprendizes (tradução livre), ou seja, aquelas que deram os primeiros passos para a implantação da Indústria 4.0.

Para aumentar o nível de maturidade para leaders, as empresas learners precisam instalar uma planta de produção com infraestrutura e equipamentos integrados por TI; expandir o compartilhamento de informações integradas no sistema tanto no ambiente interno da empresa quanto externo; analisar sistematicamente os usos potenciais de dados; aumentar o nível de serviços orientados por dados; e, incrementar os programas de treinamento e desenvolvimento profissional por meio de uma avaliação sistemática das necessidades, com a utilização de tecnologias como realidade virtual aumentada para o treinamento dos funcionários.

\section{CONSIDERAÇÕES FINAIS}

O estudo objetivou traduzir, adaptar e aplicar um instrumento de avaliação de maturidade da Indústria 4.0 em uma Empresa Estratégica de Defesa. Além do instrumento, buscou-se abordar o tema fundamentado teoricamente por meio dos 
artigos científicos internacionais mais citados na base de dados Scopus, conforme busca realizada em 02 de maio de 2019.

Assim, do ponto de vista teórico e acadêmico, o questionário (Apêndice) contribuirá com a coleta de dados para avaliar o nível de maturidade de outras EED, além de outras empresas de manufatura de diferentes setores, com a finalidade de identificar as estratégias e o status de implementação da Indústria 4.0.

Quanto às limitações da pesquisa, aponta-se que os dados avaliados empiricamente poderiam ser validados por meio de uma estatística descritiva, o que certamente geraria uma confiança maior nos resultados, porém, seria necessária uma amostra maior das empresas participantes, não sendo objeto deste estudo. No entanto, a análise qualitativa não invalida a pesquisa, pois ao se descrever um fenômeno, a literatura a aponta como a mais adequada para estimular o desenvolvimento teórico de modo mais abrangente e coerente com a realidade social em que estão inseridos os respondentes.

Como sugestão para pesquisas futuras, recomenda-se a realização de entrevistas junto aos empresários dos setores de manufatura com o escopo de investigar suas percepções sobre as possibilidades e limitações para se avançar rumo à transformação digital.

Finalmente, o modelo de avaliação do nível de maturidade não pretende demonstrar que o caminho em direção à Indústria 4.0 é simples, tampouco fácil, no entanto, o instrumento permite contribuir para a percepção dos gestores das empresas e a análise das capacidades atuais e necessidades futuras das empresas, fornecendo elementos para o processo decisório em relação às novas tendências tecnológicas advindas da $4^{a}$ revolução industrial.

\section{Referências}

Backlund, F., Chronéer, D. \& Sundqvist, E. (2014). Project management maturity models-A critical review: A case study within Swedish engineering and construction organizations. Procedia-Social and Behavioral Sciences, v. 119, p. 837-846. DOI: https://doi.org/10.1016/j.sbspro.2014.03.094

Berger, R. (2014). Industry 4.0: The new industrial Revolution. How Europe will succeed. Roland Berger Strategy Consultants, March. Recuperado em 12 de maio, 2019, de http://www.iberglobal.com/files/Roland_Berger_Industry.pdf

Bibby, L. \& Dehe, B. (2018). Defining and assessing industry 4.0 maturity levels - case of the defence sector, Production Planning \& Control. DOI: https://doi.org/10.1080/09537287.2018.1503355 
Borsa, J. C., Damásio, B. F. \& Bandeira, D. R. (2015). Adaptação e validação de instrumentos psicológicos entre culturas: Algumas considerações. Paidéia, 22(53), 423-432. DOI: http://dx.doi.org/10.1590/1982-43272253201314

Centro de Apoio a Sistemas Logísticos de Defesa. (2019). Catálogo de Empresas de Interesse da Defesa. Recuperado em 10 de maio, 2019, de https://caslode.defesa.gov.br:8443/ceid/principal.seam

Correa Filho, S. L. S., Barros, D. C., Castro, B. H. R. de, Fonseca, P. V. D. R., \& Gornsztejn, J. (2013). Panorama sobre a indústria de defesa e segurança no Brasil. BNDES Setorial, Rio de Janeiro, n. 38, p. 373-408, set.

Ministério da Defesa. (2019). Comissão Mista da Indústria da Defesa. Recuperado em 12 de maio, 2019, de https://www.defesa.gov.br/industria-de-defesa/comissaomista-da-industria-de-defesa

Decreto $n$. 7.970, de 28 de março de 2013. (2013). Regulamenta dispositivos da Lei no 12.598, de 22 de março de 2012, que estabelece normas especiais para as compras, as contratações e o desenvolvimento de produtos e sistemas de defesa, e dá outras providências. Brasília, DF. Recuperado em 10 de junho, 2019, de http://www.planalto.gov.br/ccivil_03/_Ato2011-2014/2013/Decreto/D7970.htm

Dombrowski, U \& Wagner, T. (2014). Mental strain as field of action in the 4th industrial revolution. Procedia CIRP, v. 17, p. 100-105, 2014. DOI: https://doi.org/10.1016/j.procir.2014.01.077

Dos Santos, C. F., et al. (2017). Mapping the Conceptual Relationship among Data Analysis, Knowledge Generation and Decision-making in Industrial Processes. Procedia Manufacturing, v. 11, p. 1751-1758. DOI: https://doi.org/10.1016/j.promfg.2017.07.305

Erol, S., Schumacher, A. \& Sihn, W. (2016). Strategic guidance towards Industry 4.0 - a three-stage process model. In: International Conference on Competitive Manufacturing (COMA16), Stellenbosch, South Africa. Recuperado em 15 maio, 2019, de

https://www.researchgate.net/publication/286937652_Strategic_guidance_towards_ Industry_40_-_a_three-stage_process_model

Godoy, A. S. (1995). Pesquisa qualitativa: tipos fundamentais. Revista de Administração de Empresas, São Paulo, v. 35, n. 3, p. 20-29, maio/jun. DOI: http://dx.doi.org/10.1590/S0034-75901995000300004

Indústria de Material Bélico do Brasil. (2019). Institucional. Recuperado 09 de maio, 2019, de http://www.imbel.gov.br/institucional/quem-somos

Kagermann, H., Wahlster, W. \& Helbig, J. (2013). Recommendations for implementing the strategic initiative. Industrie 4.0: Securing the future of German manufacturing industry. Final report of the Industrie 4.0 Working Group. Acatech, Forschungsunion. Recuperado em 16 de maio, 2019, de https://www.acatech.de/Publikation/recommendations-for-implementing-thestrategic-initiative-industrie-4-0-final-report-of-the-industrie-4-0-working-group/

Langston, C. \& Ghanbaripour, A. N. (2016). A Management Maturity Model $(\mathrm{MMM})$ for project-based organisational performance assessment. Construction 
Economics and Building, v. 16, n. 4, p. 68-85. DOI: http://dx.doi.org/10.5130/AJCEB.v16i4.5028

Lee, J. (2013). Industry 4.0 in Big Data Environment. Tech.News Strategy, 26, pp. 8-9. Recuperado em 12 de maio, 2019, de https://www.researchgate.net/publication/285163697_Industry_40_in_Big_Data_En vironment

Liao, Y. et al. (2017). The Role of Interoperability in The Fourth Industrial Revolution Era. IFAC-PapersOnLine, v. 50, Issue 1, July, p. 12434-12439. DOI: https://doi.org/10.1016/j.ifacol.2017.08.1248

Lichtblau K., Stich, V., Bertenrath, R., Blum, M., Bleider, M., Millack, A., Schmitt, K., Schmitz, E. \& Schröter, M. (2015). Industrie 4.0-Readiness Online Self-Check for Businesses. Recuperado em 10 de maio, 2019, de https://www.industrie40readiness.de/?lang $=$ en

Morais, R., \& Monteiro, R. (2019). An Assay On The Impact of Industry 4.0 in The Operations Area. International Journal of Professional Business Review, 4(2), 4350. DOI: http://dx.doi.org/10.26668/businessreview/2019.v4i2.134

PricewaterhouseCoopers. (2016). Global Industry 4.0 Survey. Recuperado em 15 de maio, 2019, de https://www.pwc.com/gx/en/industries/industries-4.0/landingpage/industry-4.0-building-your-digital-enterprise-april-2016.pdf

Qin, J., Liu, Y. \& Grosvenor, R. (2016). A Categorical Framework of Manufacturing for Industry 4.0 and Beyond. Procedia CIRP, v. 52, p. 173-178. DOI: https://doi.org/10.1016/j.procir.2016.08.005

Rocha et al. (2018). Ecosystem of Innovation in Industry 4.0: the case of collaborations in Startups in Brazil. International Journal For Innovation Education and Research, v. 6, p. 26-38. DOI: https://doi.org/10.31686/ijier.Vol6.Iss12.1248

Santos, K. et al. (2017). Opportunities Assessment of Product Development Process in Industry 4.0. Procedia Manufacturing, v. 11, p. 1358-1365. DOI: https://doi.org/10.1016/j.promfg.2017.07.265

Schuh, G., Anderl, R., Gausemeier, J., ten Hompel, M. \& Wahlster, W. (2017). Industrie 4.0 Maturity Index. Managing the Digital Transformation of Companies. Munich: Herbert Utz. Recuperado em 15 de maio, 2019, de https://www.acatech.de/wpcontent/uploads/2018/03/acatech_STUDIE_Maturity_Index_eng_WEB.pdf

Schumacher, A., Erol, S. \& Sihn, W. (2016). A maturity model for assessing Industry 4.0 readiness and maturity of manufacturing enterprises. Procedia CIRP, v. 52, p. 161-166. DOI: https://doi.org/10.1016/j.procir.2016.07.040

Silva, M., Meza, M., Oliveira, A., \& Procopiuck, M. (2018). Intraempreendedorismo no Setor Público: Análise do Comportamento Empreendedor de Gestores Públicos Municipais por Meio do Carland Entrepreneurship Index (CEI). Revista de Empreendedorismo e Gestão de Pequenas Empresas, 7(2), 67-114. doi: http://dx.doi.org/10.14211/regepe.v7i2.699 
Silveira Gontijo, T., \& Motta Alves, F. (2019). A Bibliometric study on Industry 4.0. International. Journal of Professional Business Review, 4(2), 35-42. doi: http://dx.doi.org/10.26668/businessreview/2019.v4i2.112

Tao, F., Cheng, J., Qi, Q., Zhang, M., Zhang, H. \& Sui, F. (2018). Digital twindriven product design, manufacturing and service with big data. The International Journal of Advanced Manufacturing Technology, 94(9-12), 3563-3576. DOI: https://doi.org/10.1007/s00170-017-0233-1

Wang, S., Wan, J., Zhang, D., Li, D. \& Zhang, C. (2016). Towards smart factory for industry 4.0: a selforganized multi-agent system with big data based feedback and coordination. Computer Networks, 101, 158-168. DOI: https://doi.org/10.1016/j.comnet.2015.12.017

Wee, D., Kelly, R., Cattell, J., \& Breunig, M. (2015). Industry 4.0: How to navigate digitization of the manufacturing sector. McKinsey Digital. Recuperado em 25 de maio, 2019, de https://www.mckinsey.com/business-functions/operations/ourinsights/industry-four-point-o-how-to-navigae-the-digitization-of-the-manufacturingsector 
Apêndice

\section{Dados da Empresa}

1. Empresa

2. Ramo de Atividade

3. Porte

Microempresa (até 19 colaboradores

Pequeno porte (20 até 99 colaboradores

Médio porte (100 até 499 colaboradores)

Grande porte (acima de 500 colaboradores)

4. Cargo/Função do respondente

5. Área do conhecimento (Formação do Respondente)

6. Por ocasião da publicação dos resultados desta pesquisa, em congresso acadêmico ou revista científica, os dados abertos da empresa poderão ser citados, como nome, porte e setor de atividade, preservando o anonimato dos respondentes?

Sim
Não

7. Caso deseje receber os resultados da pesquisa favor informar um e-mail

\section{Estratégia e Organização}

8. Qual o nível de envolvimento, apoio e conhecimento das lideranças da empresa (Presidência, CEO e Direção) com relação ao tema Indústria 4.0 ?

Baixo - as lideranças não reconhecem as oportunidades e desafios da Indústria 4.0 e não possuem conhecimento sobre questões digitais

Médio - Baixo, as lideranças reconhecem a importância do tema e estão em busca de maiores informações para a tomada de decisão

Médio - Alto, as lideranças reconhecem a importância e entendem as oportunidades de desafios para a empresa e estão definindo sua estratégia de transformação digital

Alto - as lideranças têm conhecimento sobre a Indústria 4.0, e reconhecem sua importância, oportunidades e desafios, bem como já possuem uma visão e planejamento estratégico para transformação digital da empesa

9. Qual o nível atual de colaboração da sua empresa com parceiros, fornecedores e/ou clientes para o desenvolvimento de produtos e serviços?

\begin{tabular}{llllll} 
& 1 & 2 & 3 & 4 & \\
\hline Baixa & 0 & 0 & 0 & 0 & Alta \\
\hline
\end{tabular}


10. Como você define a estratégia da sua empresa para a implementação da Indústria 4.0?
Não há estratégia
Iniciativas Piloto em Planejamento
Estratégia em Desenvolvimento
Estratégia Formulada
Estratégia em Implementação

11. Sua empresa utiliza indicadores para rastrear o status de implementação da Indústria 4.0?
Sim, nós temos um sistema de indicadores que consideramos apropriados
Sim, nós temos um sistema de indicadores que nos dá alguma orientação
Não, nossa abordagem ainda não está claramente definida

12. Quais áreas da empresa receberam investimentos na implantação de Indústria 4.0 nos últimos dois anos?

\begin{tabular}{|c|c|c|c|c|}
\hline & $\begin{array}{c}\text { Alto } \\
\text { Investimento }\end{array}$ & $\begin{array}{c}\text { Médio } \\
\text { Investimento }\end{array}$ & $\begin{array}{c}\text { Pouco } \\
\text { Investimento }\end{array}$ & $\begin{array}{c}\text { Sem } \\
\text { Investimentos }\end{array}$ \\
\hline$P \& D$ & & & & \\
\hline Produçãc & & & & \\
\hline Compras & & & & \\
\hline Logística & & & & \\
\hline Vendas & & & & \\
\hline Serviço & & & & \\
\hline TI & & & & \\
\hline
\end{tabular}

13. Quais áreas da empresa receberão investimentos na implantação de Indústria 4.0 nos próximos 5 anos?

\begin{tabular}{lcccc}
\hline & $\begin{array}{c}\text { Alto } \\
\text { Investimento }\end{array}$ & $\begin{array}{c}\text { Médio } \\
\text { Investimento }\end{array}$ & $\begin{array}{c}\text { Pouco } \\
\text { Investimento }\end{array}$ & $\begin{array}{c}\text { Sem } \\
\text { Investimentos }\end{array}$ \\
\hline P\&D & $\mathbf{O}$ & $\mathbf{O}$ & $\mathbf{O}$ \\
Comprasuão/manufatura & $\mathbf{O}$ & $\mathbf{O}$ & $\mathbf{O}$ & $\mathbf{O}$
\end{tabular}




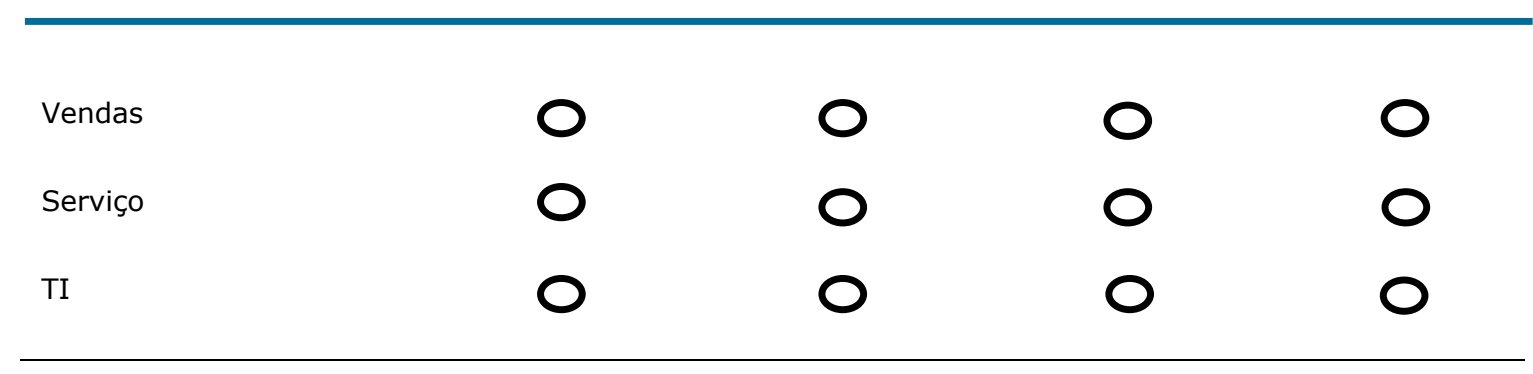

14. Como os dados apoiam o processo de tomada de decisões estratégicas?

Os dados são coletados manualmente e disponibilizados em planilhas eletrônicas

Os dados podem ser acessados diretamente dos sistemas de informação corporativos

Os dados são coletados e analisados por sensores em tempo real

Os dados são coletados e analisados por sistemas de inteligência artificial

Os dados são armazenados em sistema de nuvem digital, permitindo a prospecção de cenários

Dados não são coletados/utilizados

15. Em quais áreas sua empresa possui tecnologia sistemática e gerenciamento de inovação?

TI

Desenvolvimento de produtos

Serviços

Centralizada, em gestão integrativa

Não possui

\section{Fábrica inteligente}

\section{Infraestrutura de Equipamentos}

16. Como você avalia a infraestrutura dos equipamentos sobre as seguintes funcionalidades

\begin{tabular}{|c|c|c|c|c|}
\hline & $\begin{array}{c}\text { menos de } 25 \% \text { dos } \\
\text { equipamentos }\end{array}$ & $\begin{array}{c}\text { entre } 26 \% \text { e } \\
50 \% \text { dos } \\
\text { equipamentos }\end{array}$ & $\begin{array}{l}\text { entre de } 51 \% \text { e } \\
75 \% \text { dos } \\
\text { equipamentos }\end{array}$ & $\begin{array}{l}\text { mais de } 76 \% \\
\text { dos } \\
\text { equipamentos }\end{array}$ \\
\hline $\begin{array}{l}\text { Máquinas/sistemas podem } \\
\text { ser controlados através de } \\
\text { TI }\end{array}$ & & & & \\
\hline $\begin{array}{l}\text { M2M: comunicação entre } \\
\text { máquinas para otimização } \\
\text { do processo }\end{array}$ & & & & \\
\hline $\begin{array}{l}\text { Interoperabilidade: } \\
\text { integração e colaboração } \\
\text { com outras } \\
\text { máquinas/sistemas } \\
\text { possíveis }\end{array}$ & & & & \\
\hline
\end{tabular}


17. Como você avalia a adaptabilidade da infraestrutura dos seus equipamentos quando se trata das seguintes funcionalidades

\begin{tabular}{|c|c|c|c|c|}
\hline & Não é relevante & $\begin{array}{l}\text { Relevante, } \\
\text { mas não } \\
\text { atualizável }\end{array}$ & Atualizável & $\begin{array}{c}\text { Alta, porque a } \\
\text { funcionalidade } \\
\text { já está } \\
\text { disponível }\end{array}$ \\
\hline $\begin{array}{l}\text { Interoperabilidade: } \\
\text { integração e colaboração } \\
\text { com outras } \\
\text { máquinas/sistemas } \\
\text { possíveis }\end{array}$ & & & & \\
\hline $\begin{array}{l}\text { M2M: comunicação entre } \\
\text { máquinas }\end{array}$ & & & & \\
\hline
\end{tabular}

\section{Modelo digital de fábrica}

18. A digitalização da fábrica possibilita a criação de um modelo digital. A empresa coleta dados durante a produção
Sim, todos os dados
Sim, mas apenas alguns dados
Os dados não estão sendo coletados

19. Quais dados sobre suas máquinas, processos e produtos, bem como defeitos e suas causas são coletados durante a produção, e de que forma são coletados

\begin{tabular}{lll}
\hline & Sim, manualmente & $\begin{array}{c}\text { Sim, } \\
\text { automaticamente }\end{array}$ \\
\hline Dados de inventário & Não \\
Tempo de ciclo de produção & & \\
Capacidade de utilização do \\
equipamento
\end{tabular}

20. Onde os dados coletados são utilizados

Manutenção preditiva 
Otimização de processos logísticos

Transparência de todo o processo de produção

Gestão da Qualidade

Controle da produção

Otimização do consumo de recursos (material, energia elétrica)

Os dados não são utilizados

21. Os sistemas abaixo listados são utilizados e possuem interface com o sistema central da empresa?

\begin{tabular}{|c|c|c|c|}
\hline & $\begin{array}{l}\text { É utilizado, com } \\
\text { interface com o } \\
\text { sistema central }\end{array}$ & $\begin{array}{l}\text { É utilizado, sem } \\
\text { interface com o } \\
\text { sistema central }\end{array}$ & Não é utilizado \\
\hline \multicolumn{4}{|l|}{$\begin{array}{l}\text { MES - Sistema de execução de } \\
\text { manufatura }\end{array}$} \\
\hline \multicolumn{4}{|l|}{$\begin{array}{l}\text { ERP - Gestão de planejamento de } \\
\text { recursos }\end{array}$} \\
\hline \multicolumn{4}{|c|}{ PLM - Gestão do ciclo de vida do produto } \\
\hline \multicolumn{4}{|l|}{ PDM - Gestão de dados do produto } \\
\hline \multicolumn{4}{|l|}{$\begin{array}{l}\text { PPS - Sistema de Planejamento da } \\
\text { Produção }\end{array}$} \\
\hline \multicolumn{4}{|c|}{ PDA - Aquisição de dados de manufatura } \\
\hline \multicolumn{4}{|l|}{ MDC - Aquisição de dados de máquina } \\
\hline \multicolumn{4}{|l|}{$\begin{array}{l}\text { CAD - Projeto/desenho auxiliado por } \\
\text { computador }\end{array}$} \\
\hline \multicolumn{4}{|c|}{ SCM - Gestão da cadeia de suprimentos } \\
\hline $\begin{array}{l}\text { SCADA - Controle de supervisão e } \\
\text { aquisição de dados }\end{array}$ & & & \\
\hline
\end{tabular}

\section{Operações inteligentes}

Integração vertical e horizontal

22. Nos setores abaixo há o compartilhamento de informações internas do sistema entre departamentos?

\begin{tabular}{lcc}
\hline P\&D & Sim & Não \\
Produção/fabricação & 0 & 0 \\
\hline
\end{tabular}




\begin{tabular}{lll}
\hline Aquisição & $\mathbf{O}$ & $\mathbf{0}$ \\
Logístico & $\mathbf{O}$ & $\mathbf{0}$ \\
Vendas & $\mathbf{O}$ & $\mathbf{O}$ \\
Finanças/contabilidade & $\mathbf{O}$ & $\mathbf{O}$ \\
TI & $\mathbf{O}$ & $\mathbf{0}$ \\
\hline
\end{tabular}

23. Nos setores abaixo há o compartilhamento de informações internas do sistema com consumidores e/ou fornecedores?

\begin{tabular}{lcc}
\hline & Sim & Não \\
\hline P\&D & 0 & 0 \\
Produção/fabricação & 0 & 0 \\
Aquisição & 0 & 0 \\
Logístico & 0 & 0 \\
Vendas & 0 & 0 \\
Finanças/contabilidade & 0 & 0 \\
Serviços & 0 & 0 \\
TI & 0 & 0 \\
\hline
\end{tabular}

24. Uma das aplicabilidades da Indústria 4.0 é que uma peça pode ser guiada autonomamente através da linha de produção. Sua empresa possui essa aplicabilidade?

Sim, entre empresas

Sim, mas apenas em áreas selecionadas

Sim, mas apenas nas fases de teste e piloto

Não possui

25. Sua empresa possui processos que respondam de forma autônoma/automática, em tempo real, às mudanças que ocorram durante a produção?
Sim, entre empresas
Sim, mas apenas em áreas selecionadas
Sim, mas apenas nas fases de teste e piloto
Não possui 


\section{Segurança de dados e comunicações}

26. Como a TI é organizada na sua empresa?

Não há departamento interno de TI (usamos provedor de serviços)

Temos um departamento central de TI

Temos uma seção de TI em cada setor da empresa (produção, desenvolvimento de produtos etc.)

Temos especialistas de TI em cada setor da empresa

27. Quais soluções de segurança cibernética são utilizadas na empresa?

\begin{tabular}{|c|c|c|c|c|}
\hline & $\begin{array}{l}\text { Não é } \\
\text { relevante }\end{array}$ & $\begin{array}{l}\text { Solução } \\
\text { planejada }\end{array}$ & $\begin{array}{l}\text { Solução em } \\
\text { Implantação }\end{array}$ & $\begin{array}{c}\text { Solução em } \\
\text { Funcionamento }\end{array}$ \\
\hline $\begin{array}{l}\text { Segurança no armazenamento } \\
\text { interno de dados }\end{array}$ & & & & \\
\hline $\begin{array}{l}\text { Segurança de dados por meio de } \\
\text { serviços em nuvem }\end{array}$ & & & & \\
\hline $\begin{array}{l}\text { Segurança das comunicações para } \\
\text { troca interna de dados }\end{array}$ & & & & \\
\hline $\begin{array}{l}\text { Segurança de Comunicações para } \\
\text { troca de dados com parceiros de } \\
\text { negócios }\end{array}$ & & & & \\
\hline
\end{tabular}

28. Sua empresa utiliza serviços de nuvem (cloud computing)?

\begin{tabular}{lc}
\hline Sim & $\begin{array}{c}\text { Não, mas estamos } \\
\text { planejando usar }\end{array}$ \\
Análise de dados & Simare baseado em nuvem
\end{tabular}

\section{Produtos inteligentes}

29. Quais das seguintes funcionalidades estão presentes nos seus produtos?

\begin{tabular}{|c|c|c|c|c|c|}
\hline & Inexistente & $\begin{array}{l}\text { Menos de } \\
25 \% \text { dos } \\
\text { produtos } \\
\text { do } \\
\text { portfólio }\end{array}$ & $\begin{array}{l}\text { Entre } 26 \% \text { e } \\
50 \% \text { dos } \\
\text { produtos do } \\
\text { portfólio }\end{array}$ & $\begin{array}{l}\text { Entre } 51 \%- \\
75 \% \text { dos } \\
\text { produtos do } \\
\text { portfólio }\end{array}$ & $\begin{array}{c}\text { Mais de } 75 \% \\
\text { dos produtos } \\
\text { do portfólio }\end{array}$ \\
\hline $\begin{array}{l}\text { Descritiva - Captura } \\
\text { dados das condições do } \\
\text { produto, ambiente e } \\
\text { operações }\end{array}$ & & & & & \\
\hline
\end{tabular}


Diagnóstico - examina as causas de falhas e

O

0

0

0

0

redução de desempenho

0

O

0

0

0

causar falhas

Prescritiva -

Identificações para

melhoria do desempenho

ou correção de falhas

O

$0 \quad 0$

○

0

30. Qual é o nível de customização dos produtos?

12

3

4

\begin{tabular}{l|l|l|l|l|l}
\hline $\begin{array}{l}\text { Não é possível } \\
\text { customizar (produção } \\
\text { em massa) }\end{array}$ & $\mathbf{0}$ & $\mathbf{O}$ & $\mathbf{O}$ & $\begin{array}{l}\text { Completamente (o } \\
\text { cliente escolhe como } \\
\text { quer o produto) }\end{array}$ \\
\hline
\end{tabular}

\section{Serviços orientados por dados}

31. Os dados reunidos no processo de produção e na fase de uso permitem novos serviços. Sua empresa oferece tais serviços?

Sim, e estamos integrados com nossos clientes

Sim, mas sem integração com nossos clientes

Não oferecemos o serviço

32. Qual percentual da receita da empresa são provenientes dos serviços orientados por dados?

$0 \%$

- 1 a $24 \%$

- 25 a $49 \%$

- 50 a $74 \%$

- 75 a $100 \%$

33. Frequentemente, os dados coletados e armazenados não são usados. Qual percentual dos dados que você coleta são utilizados?
$0 \%$
1 a $20 \%$
21 a $50 \%$
Acima de $50 \%$ 
34. Os dados da sua empresa são coletados na fase de uso?

Sim

Coletamos os dados, mas não os analisamos

Não coletamos dados na fase de uso

\section{Funcionários}

35. Como você avalia as habilidades de seus funcionários quando se trata dos requisitos da Indústria 4.0?

\begin{tabular}{|c|c|c|c|c|}
\hline & Não relevante & Inexistente & $\begin{array}{c}\text { Existente, mas } \\
\text { inadequada }\end{array}$ & Adequada \\
\hline \multicolumn{5}{|l|}{$\begin{array}{c}\text { Infraestrutura de } \\
\text { TI }\end{array}$} \\
\hline \multicolumn{5}{|l|}{$\begin{array}{l}\text { Tecnologia de } \\
\text { automação }\end{array}$} \\
\hline \multicolumn{5}{|l|}{ Análise de dados } \\
\hline \multicolumn{5}{|l|}{$\begin{array}{c}\text { Segurança de } \\
\text { dados/segurança } \\
\text { de comunicações }\end{array}$} \\
\hline \multicolumn{5}{|l|}{$\begin{array}{l}\text { Desenvolvimento } \\
\text { ou aplicação de } \\
\text { sistemas de } \\
\text { assistência }\end{array}$} \\
\hline \multicolumn{5}{|l|}{$\begin{array}{l}\text { Software de } \\
\text { colaboração }\end{array}$} \\
\hline $\begin{array}{l}\text { Habilidades não } \\
\text { técnicas }\end{array}$ & & & & \\
\hline
\end{tabular}

36. Nas habilidades inexistentes ou inadequadas para a Indústria 4.0, como a empresa tem buscado supri-las?

Convênios e parcerias com Instituições de Ciência e Tecnologia (IC\&T)

Convênios e parcerias com Programas de Pós-graduação (Mestrado e Doutorado)

Convênios e parcerias com escolas técnicas e instituições de ensino superior

Contratação de empresas de consultoria para a capacitação dos funcionários

Participação em Eventos, Seminários e Congressos acadêmicos

Não temos programas de capacitação e treinamento para a Indústria 4.0 